\title{
O CONCEITO DE GÉNIO NAS LIÇÕES DE ANTROPOLOGIA DE KANT
}

\author{
Fernando M. F. Silva* \\ frndsilva@portugalmail.pt
}

RESUMO Seguindo a elevação de outros dons naturais do espírito humano a categorias ou princípios estéticos, o que ocorreria gradualmente durante o século XVIII, o génio e as suas várias problemáticas tornam-se uma das mais prementes questões na agenda filosófica da época. Entre outros, a questão assume particular relevância na filosofia de Immanuel Kant, e isso não apenas na sua obra publicada, mas também na sua actividade como Professor. $O$ presente texto propõe-se abordar a questão do génio nas lições de antropologia do filósofo (1772-1796), e, tomando isto como ensejo, cumprir dois objectivos centrais: em primeiro lugar, traçar uma brevissima história do conceito desde o século XVII até Kant, a fim de perceber que emprego desta faria o filósofo, e como ele próprio se associa ou dissocia desta. Segundo, compreender o modo como, dada a sua percepção histórica do termo, a teoria do génio em Kant trilha um curso singular, distinto em relação ao dos seus contemporâneos, $e$ que faz com que o génio ostente uma posição central no seio da sua própria teoria; pois, na visão de Kant, o génio não só desempenha um importante papel como mediador das faculdades do ânimo humano, como é ainda peça indispensável na boa proporção entre estes e na insuspeitada produção de conhecimento por isto gerada.

Palavras-chave Kant, génio, ingenium, proporção, poesia.

ABSTRACT Following the ascension of other natural gifts of the human spirit to the condition of categories or aesthetic principles, which would occur

* Universidade de Lisboa. Artigo recebido em 17/12/2015 e aprovado em 22/01/2016. 
gradually during the $18^{\text {th }}$ century, the topic of genius and its various issues becomes one of the most important questions in the philosophical agenda of the time. Among others, the question assumes particular relevance in Immanuel Kant's philosophy, not only in his published work, but also in his activity as a professor. The following text intends to approach the question of genius in the philosopher's Lectures on Anthropology (1772-1796), and taking the latter into account, to fulfil two central objectives: first, to etch a brief history of the concept from the $17^{\text {th }}$ century until Kant, so as to realize what use Kant would make of this evolution, and how he himself associates or dissociates from it. Secondly, we intend to understand how Kant's theory of genius describes its own singular course, different from the ones of his contemporaries, and renders the genius a central piece within his own theory; for, in Kant's view, the genius not only plays an important role as mediator of the faculties of the spirit, but it is also an indispensable factor in the proportion between the latter, and in the unsuspected production of knowledge thus generated.

Keywords: Kant, genius, ingenium, proportion, poetry.

\section{Introdução}

É sabido que, para além do condão de nos mostrarem um outro Kant, por certo menos conhecido, mas não menos relevante, as lições de antropologia do filósofo têm como um dos seus principais interesses desvelar a génese de várias vertentes do seu pensamento: por exemplo, do seu pensamento político, cuja matriz cosmogónica aí surge; do seu pensamento crítico, no germe da sua noção de teleoformidade da natureza, ou ainda do seu pensamento estético, como ele viria a ser exposto na "Crítica da Faculdade de Julgar".

Esta última vertente é para nós de especial interesse; e entre os tópicos deste cariz aí abordados, vários seriam merecedores de menção, como o engenho, o gosto ou a memória. Um, porém, serve o anterior propósito na perfeição, e quase parece englobar todos os outros nessa sua função: refiro-me ao génio: por um lado, um conceito com uma vetusta e singular história, muito anterior às lições, mas cujo desenlace, ocorrido justamente no século destas, viria a influenciar a visão que deste teria o filósofo; por outro, um tema que não é de todo estranho a Kant, que Kant não confinaria a estas lições, e ao qual por isso dedicamos o presente ensaio; tanto mais porque o tema, sendo de reconhecida importância em Kant, é geralmente desligado da sua história, e por isso abordado 
por outros prismas que não o das lições de antropologia, ${ }^{1}$ as quais a nosso ver podem ter nisso grande relevância e ajudar a explicar o termo como ele surgiria posteriormente.

Assim, os objectivos principais deste ensaio são:

Em primeiro lugar, traçar uma breve, embora necessariamente incompleta história do conceito desde o século XVI até à época de Kant; isto é, desde uma época em que o génio vigora ainda na acepção clássica de genius, até um tempo em que ele surge como ingenium; e dentro deste segundo membro da transição, desde uma fase em que o génio é $d o m$, para outra em que ele vem a ser talento natural, e por fim para outra em que ele se torna categoria estética por excelência. Como fio condutor nesta evolução, servem os exemplos da generalizada mutação linguística e semântica da palavra.

Por fim, mostrar que Kant não desconhecia esta história, e que se associa à mesma; mas que, não obstante, Kant vê no conceito outra determinação, mas também maiores potencialidades que aquelas que o seu tempo lhe atribuía; a saber, vendo no génio o estatuto intermédio de uma capacidade do ânimo [Gemüthsfähigkeit] operando entre faculdades contrárias, e por isso mesmo incumbindo-o da fulcral tarefa de gerar harmonia e proporção entre faculdades, e com isso trazer benefício à faculdade de conhecer do espírito humano. ${ }^{2}$

\section{Breve história do conceito génio}

Ao se procurar a genuína origem do termo génio, ou sequer os primeiros rudimentos de uma história do termo, cedo se constata que tais buscas nos levam a tactear por um fio da história das línguas que o tempo apagou.

Ponto assente, e o único a partir do qual parece ser possível encetar uma breve história do conceito em séculos mais recentes, é aquele em que não obstante os

1 O interesse pela questão do génio em Kant é inegável, e a bibliografia daí decorrente não é escassa; desta, salientaria, por exemplo, BÄUMLER, A. "Das Irrationalitätsproblem in der Ästhetik und Logik des 18. Jahrhunderts bis zur Kritik der Urteilskraft". Darmstadt: Wissenschaftliche Buchgesellschaft, 1981; SCHLAPP, O. "Kants Lehre vom Genie und die Entstehung der Kritik der Urteilskraft". Göttingen: Vandenhoeck \& Ruprecht, 1901; GIORDANETTI, P. "Etica, genio e sublime in Kant". Mimesis, 2012. Já a questão do génio nas lições de antropologia do filósofo, por razões óbvias, é mais limitada. Ainda assim, destacaríamos BECKENKAMP, J. "Kant und Gerard über Einbildungskraft”. In: B. Dörflinger et al. (ed.). Kant's Lectures/ Kants Vorlesungen. Berlin/Boston: De Gruyter, 2015. pp. 133-142; GUYER, P. "Beauty, Freedom and Morality: Kant's Lectures on Anthropology and the Development of his Aesthetic Theory”. In: B. Jacobs (ed.). Essays on Kant's Anthropology. Cambridge: Cambridge UP, 2003. pp. 135-163.

2 Com respeito às citações de autor, recorremos ao método (Nome, abreviatura da obra, número de volume, número de página), sendo que a abreviatura correspondente se encontra discriminada na bibliografia. As citações em questão, por razões óbvias, foram deixadas nos seus originais. Com respeito às citações de Kant, estas serão referenciadas na maneira tradicional. A tradução das mesmas para português é da minha autoria e responsabilidade. 
dicionários de várias línguas parecem concordar: em primeiro lugar, que génio provém quer do grego gen, gerar (não sem referência a genitalia, engendrare), quer do correspondente latino gigno, gignere, o criar espontâneo e próprio, ser pai de; e em segundo lugar que, com o tempo, estas noções viriam a resultar em duas outras, de cuja evolução semântica conjunta génio parece ser o produto final: a saber, os claramente aparentados termos latinos genius (de gen) - na religião romana um espírito protector, ${ }^{3}$ um anjo ou demónio (daimon) que nasce com o homem, e morre com ele -, e ingenium (de gigno), um talento íngénito, um dom natural para, sem instrução, criar aquilo que é impossível para outros. ${ }^{4}$ Dois termos que, é sabido, significavam na origem coisas diferentes, e trilhariam cursos diversos; mas que posteriormente viriam a entrelaçar os seus campos semânticos, a ponto de serem entendidos quase como um só, ${ }^{5}$ e originariam então o português génio, o espanhol genio, o inglês genius, o francês genie-e, o que nos interessa aqui mais, o alemão Genie.

Ora, ainda que os primeiros episódios de tal evolução não sejam visíveis, há porém outros que se deixam reconstituir, e sobre os quais queremos debruçar-nos; a saber, o fenómeno do trilho percorrido pelo termo inglês genius a partir do século XVI, a sua transformação pelo francês em genie, e o seu ulterior suscitar do alemão Genie, no século XVIII, pouco antes de Kant. Numa palavra, pois, visamos aqui o episódio da transição do termo génio entre genius e ingenium, como ela se dá no espaço de dois séculos.

Assim, por volta do século XVI, o termo genius era corrente por toda a Europa (Grimm, DW, 3396); e isso, quase sem excepção, no seu significado latino de espírito protector dos homens: ou, como o diz Stephanus, no seu Dictionarium, seu latinae lingae thesaurus (1531): "Genius, Ab aliquibus dicitur vis \& naturae deus hospitalis , \& ipsa voluptas" (Stephanus, DLLT, 339). Isto, aliás, era deveras natural: pois embora ambos os termos figurem já à data, o

3 Na sua 1a edição, a "Encyclopaedia Britannica" não o menciona; mas na sua 1a edição em solo americano, de 1798 (equivalente à $3^{a}$ edição inglesa), fala-se até em genius como "the god who had the power of generating all things" ("Encyclopaedia", 623), "the Son of God, and the Father of men" (id.), ou ainda "tutelary god of each place" (ibid.). O "Dicionário" dos Grimm corrobora isto mesmo, e aduzem que em tempos mais recentes, esta faceta do génio não esmorecera; tanto assim, que ainda nos séculos XVII e XVIII, se fala de "die natur, ja Christus und gott selbst als genius" (Grimm, DW, 3402). Mas o culto alegórico do génio de modo algum se esgota nesta sua altura maior; pois, informam os Grimm, génio era também "genius saeculi" (id.: 3401); "der genius eines volkes, landes" (id.); "genius des vaterlandes" (id, 3402); "genius der menschheit" (id.); "das schicksal als genius" (ibid.), e ainda génio da paz, da amizade, da guerra, a ponto de haver deste incontáveis instâncias!

4 Friedrich C. Diez, no seu "Etymologisches Wörterbuch der romanischen Sprachen" (1853), diz de "Ingegno": "[...] altsp. engeño [...]; fr. engin, erfindungskraft, dsgl. künstliche maschine; von ingenium. Daher altfr. engignier, überlisten, pr. engenhar, nachstellen, it. ingegnarsi, nfr. s'ingénier, auf mittel sinnen [...]" (Diez, EwrS.1, 195). 
termo genius é porém mais vetusto do que o seu parente ingenium - a ponto, aliás, de dele dever partir a investigação sobre o génio (Grimm, DW, 3396); e portanto, até à altura, e durante alguns séculos mais, o termo genius, tendo sido extraído "da língua romana e do mundo dos pensamentos dos humanistas" (id.), e sendo por isso preeminente na Europa, demarcava-se de ingenium. ${ }^{6}$ Genius significava o espírito que ou cuidava, ou fazia incorrer em pecado o homem; e ingenium, bem dissociado deste, nada tinha a ver com tal entidade: ele era o resultado de um talento, uma qualidade ou inclinação criativa do espírito humano.

O caso mais exemplar desta adopção unívoca de genius é por certo a Inglaterra, que não a tomaria por empréstimo, antes tomaria por sua a palavra latina (Genius/genius). Assim, os usos mais antigos do termo figuram na tradução inglesa "Romaunt of the Rose", por Chaucer, na segunda metade do século XIV (King, AHCG, 12), e no poema "Confessio Amantis" (c. 1390), de John Gower (id.: 13), e não muito depois, o termo ressurge aqui e ali, em Spenser, Jonson ou Shakespeare (id.: 13-26) - sempre na já referida acepção clássica do termo. Prova disso, é que, ao se consultar um dos primeiros dicionários de língua inglesa, "The Dictionary of Syr Thomas Elyot Knyght" (1538), o autor dá de genius a seguinte entrada: "an aungell. Amonge the Paynims some supposed it to be the spirite of a man. Some dydde put two gouernours of the sowle, a good and an euyll, Bonus genius, \& malus genius". ${ }^{7}$ O mesmo é dito por Robert Cawdrey, no seu "A Table Alphabeticall" (1604): "genius, the Angell that waits on man, be it a good or euill Angell" (Cawdrey, TA, sem pág.). A partir destes registos, o termo abre lento, por vezes incerto caminho nas literaturas europeias; em França, por exemplo, um dos primeiros registos da palavra génie surge por volta de 1482, em "Vie et passion de saint Didier", de Guillaume Flameng (Perras, EE, 13), e por volta de 1500, pelas mãos de Saint-Gelais e Rabelais (id.), ${ }^{8}$ mas não seria registada por dicionários de língua francesa até ao século XVII; e na Alemanha, diz o "Dicionário" dos Grimm, há registos de genio e genius já em Hans Sachs, "Der Tod zuckt das Stüllein" (1558), e Johann Fischart, "Podagrammisch Trostbüchlein" (1577) (Grimm, DW, 3396); usos do termo, porém, que não constam ainda do "Teutscher Dictionarius" (1571), de Simon Roten, ou do "Teutsches Sprach und Weiszheit" (1616), de Henisch.

Assim, creio, os anteriores exemplos permitem-nos uma assumpção. Até ao fim do século XVI, dir-se-ia, poucos serão os casos registados de um uso de

6 Stephanus diz que "Certe à gignedo genius appellatur" (Stephanus, DLLT, 339). Mas, Segundo Breach King, "rarely did the Romans use genius to denote wit or talent" (King, AHCG, 6), e "from at least as early as Plato [...] limited recognition was given to the importance of native endowment [...]" (id.: 10).

7 Citação extraída de http://quod.lib.umich.edu/e/eebo/A21313.0001.001/1:7?rgn=div1; view=fulltext.

8 Sobre as dificuldades inerentes à compreensão dos primeiros registos de "génie", cf. Perras, EE, 54-55. 
génio que não obedeça à sua significação clássica ${ }^{9}$ e se isso é certo na literatura, ou na filosofia, tal comprova-se ainda melhor nos registos lexicográficos da época, os quais, ou por estarem na sua infância, ou por se tratar genius de um estrangeirismo, ou então porque a palavra não se tinha difundido sobejamente, não fariam até à data qualquer registo do mesmo.

Seria o século XVII, pois, o ponto de viragem - não só porque aí se dá a importante transição entre genius e ingenium, mas porque o termo génio adquire aí uma nova vida muito para além da sua anterior. ${ }^{10}$

Assim, com o decorrer do séc. XVI, surgem já esporadicamente alguns usos não-unívocos do termo, os quais, creio, poderemos considerar serem claros sinais de que já então o génio poderia ser algo mais do que genius. Rabelais, por exemplo, é nisto precursor, usando genius na nova acepção, no seu "Pantagruel", c. 1532 (Perras, EE, 13), e Scaliger, ainda no séc. XVI, segue-o nisto (Sommer, GZBW, 43-49); quase simultaneamente, em 1575, é publicado o Examen de Ingenios do espanhol Juan Huarte de San Juan, que escreve sobre o ingenio no sentido da nova concepção de génio; e para além dos Metaphysical Poets, também Philip Sidney, em “Apology for Poetry” (1579), recorre ao mesmo uso do termo (King, AHCG, 32). Ora, com que pungência a nova conotação do termo se disseminaria nas línguas europeias, apenas o poderemos supor. Certo é que a inovação é real; e são os dicionários de língua, sobretudo a partir do século XVII, que dão prova da inovação. Assim, atestando o novo uso do termo, John Bullokar diz no seu "An English Expositour" (1616): "The spirit or Soul. A good Angel, or a familiar evil Spirit” (Bullokar, EEx, sem pág.); mas logo após aduz: "Also one's natural Inclination or Propensity to do any Thing." (id.) (de notar a diferença para Cawdrey (1604)); do mesmo modo, Elisha Coles, no seu "English Dictionary" (1676), apresenta genius como "attending spirit" (Coles, ED, sem pág.), após o que diz: "also nature, fancy or inclination” (id.); na França, Cesar e Antoine Oudin dizem a respeito, no "Thresor des Trois Langues" (1645): “Génio, le genie d'un chacun, c'est le bon \& mauvais. Ange qui est baillé à un chacun dés sa Nativité, pour le garder ou luy nuire. Item, le naturel de l'homme" (Oudin, TTL, sem pág.); e na Alemanha, embora influenciado por dicionários de outras línguas, de salientar Nicolaus Volckmar, "Dictionarium

9 De referir que também na França e na Alemanha, onde genius era também já corrente, o uso da palavra era similar; supõe-se, porém, que cada uma destas línguas, não podendo referir-se ainda a genius senão como um espírito acompanhante, e não podendo recorrer sem mais ao latim ingenium, se serviriam para o efeito dos respectivos, mais antigos "esprit" e "Witz" (e na Alemanha também "Geist"), o mesmo acontecendo por certo com o "wit" inglês, que à altura por certo diferiam de génio, mas que em breve muito se prestariam ao génio sob a égide do ingenium.

10 Cf. Grimm, DW, 3398, 3407 e 3408. 
Trium Linguarum Latine, Germanice et Polonice" (1605), que diz de genius: "zu der Natur gehörig" (Volckmar, DTLL, 364).

Assim, não é difícil ver que, tanto na Inglaterra, como não muito depois na França, génio continua a ser um espírito tutelador das acções do homem (aliás, este significado é invariavelmente o primeiro a ser registado, prova da sua contínua importância). Mas, diz-se agora, génio não mais é apenas uma entidade de natureza divina que guarda ou condena os homens, e talha o destino dos mesmos. Não; pois, pouco a pouco, no espírito dos homens, a própria natureza do génio altera-se; não na sua origem inata, e tão-pouco na superioridade das suas criações, que o génio preservará também enquanto ingenium; mas, sobretudo, na acção do génio. Pois, paulatinamente, o homem prescinde da natureza exterior, ou da forma de alteridade interior que era a do genius, e, reconhecendo-a em si mesmo, enquanto sua própria interioridade, transfere esses mesmos poderes de decisão e de criação para si mesmo, tornando-os sua própria natureza (o seu natural, naturel ou nature), e tornando-se ele próprio único entre os homens. Isto é, o génio deixava de ser exclusivamente genius, e com isso adquiria uma maior amplitude de movimentos, tornava a sua acção mais individual e criativa. Do génio passava a depender uma mais inventiva, mais subjectiva criação; e ao assim proceder, pouco a pouco genius dá lugar ao... in-genium; ou, dir-se-ia, o génio externo é como que incarnado pelo espírito humano, e de característica inata e superior de todos os homens, que os unia ao divino pelo resultado das suas acções no palco da vida, o génio passa a ser traço inato apenas de alguns homens singulares, que se vêem ligados ao divino não por criações alheias, mas por criações próprias, de que apenas eles podem reclamar mérito.

Por conseguinte, a partir do século XVIII, o génio, enquanto ingenium, passava a ser não uma contingência, mas um dom ou propensão naturais do espírito humano: a saber, uma superior força do espírito humano, capaz de feitos inimitáveis, inaprendíveis, o que redundaria na inscrição do conceito de génio na paleta dos talentos humanos. Pois antes mero espectador da criação (gen), o homem era agora, cada vez mais, agente na criação (gigno); isto é, o génio, agora ingenium, agora elevado a talento ou disposição inata do ser humano para a criação original, era, ao invés de passividade do ser humano perante a voz divina, fonte de individualidade e actividade do homem; e portanto, ao passar de acto criado a acto criador - a poiein -, o génio ascenderia na cadeia das capacidades humanas, inscrever-se-ia entre elas, enquanto talento ou inclinação natural, e ganharia até entre estas um lugar de destaque. Um tal destaque, aliás, seria reconhecido um pouco por toda a Europa. Como exemplo, tome-se John Milton, que já "Pro Se Defensio" (1655) e na “Defensio 
Secunda" (1654), faz uso do novo sentido da palavra: "to obtain... the praise of learning, and of genius [doctrinae \& ingenii laudem] [...]" (King, AHCG, 33). $\mathrm{Na}$ Espanha, surge Arte de Ingenio (1642), de Baltasar Grácian, novamente associando o talento do genio a ingenio (ingenium, "Witz"); e por fim, vejam-se novos exemplos lexicográficos, de onde destaco John Kersey, "Dictionarium Anglo-Britannicum” (1708), que diz ser genius: “[...] Also a Man's natural Disposition or Indowment" (Kersey, DAB, sem pág.); César-Pierre Richelet, "Dictionnaire François" (1680), o primeiro em língua francesa integral, e o primeiro a figurar a palavra "genie", que diz deste: "Les Anciens faisoient un Dieu du Genie, mais parmi nous c'est un certain esprit naturel qui nous donne une pente à une chose. Naturel. Inclination naturelle d'une personne [Avoir un beau genie..." (Richelet, DF, 369); e, por fim, o "Dictionnaire de l'Academie" (1694), que diz sobre "genie", com clareza inequívoca: "[...] Il signifie aussi, L'inclination ou disposition naturelle, ou le talent particulier d'un chacun [...]. On dit Travailler de genie, pour dire, Faire quelque chose de la proper invention \& d'une maniére aisée \& naturelle" ("Encyclopédie".15, 517).

Assim, nos referidos países, e acompanhando a ascensão de génio a talento criativo do espírito humano, forma-se em torno do conceito toda uma crítica literária e filosófica, uma literatura especializada sobre, e como resultado do novo conceito de génio, de que poderíamos dar bastos exemplos. Mas, na Alemanha em especifico, ocorreria um último estádio, uma derradeira glorificação do conceito de génio inventivo (ingenium), porventura sensível também noutros países, mas aí mais evidente e singular. Ora, se há uma razão porque vimos omitindo o caso alemão, é porque, pelo menos até certo ponto no tempo, ele não existe. A palavra Genius, e a dada altura Genium, existiam por certo na língua alemã; mas estas significavam ainda e sempre o já referido deus tutelar dos homens, e a sua ocorrência era de tal modo rara e umbilicalmente unida à significação clássica do termo, que, sem excepção, os vários dicionários da língua não a consideravam enquanto tal, redireccionando antes o uso do termo para "Witz" ("wizzi", "witze") ou "Geist". Exemplos disto, aliás, não faltam; pois durante o século XVII, nem Georg Henisch (1616), nem Georg Schottel (1663), nem mesmo Kaspar Stieler (1691) registam a palavra nos seus dicionários. Ademais, Georg Liebe, no seu “Teutsches Wörter Büchlein” (1701), não inclui nem Genius, nem Genie, nem mesmo na secção de galicismos adoptados. E note-se que, mau grado a emergência da palavra em Wolff, Gottsched ou Lessing na primeira metade do séc. XVIII, e as referidas teorias críticas sobre o termo, nem Christoph E. Steinbach (1734), nem Johann L. Frisch (1741) 
registam ainda a palavra, nem a antiga, nem a nova, ${ }^{11}$ e não é senão aquando do dicionário de Friedrich Gladov, "A la Mode-Sprach der Teutschen, oder Compendieuses Hand-Lexicon" (1727), que a palavra "Genie" é grafada num dicionário (embora trilingue) na Alemanha ${ }^{12}$ - o que nos leva a concluir que, embora não saibamos localizar bem as primeiras ocorrências do termo, podemos porém estimar até quando ela não significou senão o que sempre significara. O mesmo é dizer: a entrada do termo Genie na língua alemã não pode estar dissociada da sua nova faceta de ingenium - pois a entrada de uma e outra são na Alemanha simultâneas, e há que situar a tardia emergência de ambas após as primeiras décadas do século XVIII; ${ }^{13}$ razão por que, dir-se-ia, até às poéticas dos suíços Joh. Jakob Bodmer e Joh. Jakob Breitinger, na década de 40, e até Lessing e Klopstock, o génio de língua alemã não é outro que não aquele que há muito fora suplantado na Inglaterra e na França.

O titubeante, incerto início de história do Genie alemão, porém, dificilmente poderia deixar antever o importante estádio que a palavra, e com ela a noção de génio como ingenium, aí viria a alcançar. Pois, por certo, na Alemanha, como em outros países, Genie, tal como génie, ou genius, eram antes de mais dom natural do espírito: inventividade, originalidade do espírito humano, mais bem ilustrada na sublimidade das suas criações únicas. Mas, a meu ver, nem o génio, nem nenhum dos talentos naturais do espírito, se quedaria por esta condição; nem na Alemanha, nem fora da Alemanha. Na Inglaterra, muito por acção de Shaftesbury e Young, e na França, por acção de Soubeiran de Scopon, o conceito de génio prosseguiria a sua evolução, cada vez mais como um conceito distinto, e núcleo central de um grupo de outros conceitos seus irmãos - justamente, os de "Witz", ou espírito. Na Alemanha, os escritos de J. C. Hamann e J. C. Lavater cumpririam o difícil, mas importante papel de preparar o estatuto do génio como categoria estética. Mas, mais centralmente ainda, caberia à Estética de Baumgarten, em 1750 - e antes mesmo de o termo Genie ser grafado em

11 Referi atrás que Nicolaus Volckmar: "Dictionarium Trium Linguarum Latine”, 1605, faz já referência a genius como próprio do natural; mas o uso, como se poderá imaginar, não era ainda consensual na Alemanha. Assim, Levinus Hulsius, Francesco Martino Ravelli: "Dittionario, Italiano-Francese-Tedesco; FranceseItaliano-Tedesco; E Tedesco-Francese-Italiano”. Frankfurt 1616, não faz sequer referência à palavra; e o "Dictionarium Latino-Sveco-Germanicum Ex Variis Probatorum Authorum Lexicis" (1640) de Jonas Petri, não é neste uso da palavra tão inequívoco. "A dictionary English, German and French" (1706), de Christian Ludwig -, esse sim, refere-se já inequivocamente a genius como "angebohrne Art, natürliche Zuneigung" (Ludwig, DEGF, 301), tal como já era uso na Inglaterra e na França. Mas nenhum destes se refere ainda a Genie, enquanto estrangeirismo tomado pela língua alemã..

12 A referência é tanto mais digna de nota, porque Gladov refere-se a "Genie" como "die angebohrne Art, Zuneigung, oder Natur eines Menschen" (Gladov, SdT, 276), deixando para "Genius" a acepção de "NaturGeist" (id.).

13 A prova é dada por Adelung, que, em 1774, se refere a "Genie" como uma palavra "das in den neuern Zeiten im Deutschen aufgenommene Franz. Wort Genie [...] abstammet” (Adelung, GKW.2, 559). 
qualquer dicionário exclusivamente de língua alemã! -, elevar a estética a domínio do saber, e assim, não só inaugurar a reflexão sobre a possibilidade de um mais fecundo conhecimento individual, proveniente do sentimento de cada um, como abrir para a noção de que esse tão singular conhecimento seja veiculado por princípios ou instrumentos estéticos, e não por mera racionalidade; a saber, justamente o génio, o "Witz", o gosto. Pois o que Baumgarten sugere, e com ele, salvaguardando as devidas diferenças, também Hamann ou Lavater, é que o génio, o "Witz", são mais do que meros talentos inatos do espírito humano, e que não bastava dissociá-los da sua anterior raíz clássica. Mais do que isso, génio, “Witz”, gosto são para o próprio espírito humano veiculadores de novas, até então inauditas cognições, adquiridas mediante a singularidade do sentimento por estes propiciado, as quais não só são inegavelmente pregnantes, como ulteriormente vêm a revelar-se até muito benfazejas para a própria razão. E portanto, numa palavra, o génio afirma-se aí, pela primeira vez, não mais apenas como dom humano, mas doravante como faculdade do espirito humano, de tão notória importância como a faculdade de julgar ou a fantasia, e de tão pungente interesse para o tesouro do conhecimento humano como estes; uma nova e crucial noção que aqui vemos no caso alemão, mas que não tardaria a propagar-se também à literatura e filosofia de outros países. Prova disto, são uma vez mais os dicionários de língua de tais países: por exemplo, Nathan Bailey, cujo "Dictionarium Britannicum" (1721) diz de génio: "the force or faculty of the soul, considered as it thinks or judges" (Bailey, DB, sem pág.); Johnson, no seu "English Dictionary" (1755) corrobora isto: "The Protecting or ruling power of men, places, or things [...]; a man endowed with superior faculties $[\ldots]$; mental power or faculties [...]; disposition of nature by which any one is qualified for some peculiar employment. [...] Nature; disposition" (Johnson, DEL, sem pág ); e, por fim, o próprio Adelung, que, no seu "Grammatischkritisches Wörterbuch" (1774), contemporâneo de Kant, e de um modo muito afim a este, é o primeiro a grafar a palavra "Genie" num dicionário de língua alemã, sob a seguinte entrada: "In engerer und gewöhnlicher Bedeutung. 1) Eigentlich, die natürliche Geschicklichkeit, gewisse Dinge leichter und besser zu vollbringen, als andern möglich ist; welche Geschicklichkeit die Folge eines bestimmten Verhältnisses aller Erkenntnißvermögen, oder eines hohen Grades aller Geisteskräfte ist." [...] 2) In noch engerer Bedeutung verstehet man unter diesem Ausdrucke zuweilen, besonders in den schönen Künsten, die zum Erfinden nöthige scharfe und schnelle Beurtheilungskraft, schnellen Witz und unerschrockenen Muth. Das Genie erschafft, das Talent setzt nur ins Werk" (Adelung, GKW, 559). 
Assim, concluir-se-ia, alcançaria o génio o último estádio da sua evolução, e assim completaria ele o seu curso como conceito central do pensar e sentir humanos - uma índole com que por certo chegaria até Kant, mas que pouco a pouco se dissiparia no século XIX, e que nos nossos dias não raras vezes é esquecida, quando não aviltada.

\section{O conceito de ingenium em Kant}

Fixemo-nos, pois, no período em questão; a saber, a segunda metade do século XVIII, período em que o génio passa a gozar de um estatuto único na sua longa história.

Constatámos que a partir do século XVIII, surge por toda a Europa, primeiro gota a gota, e depois como uma torrente, toda uma literatura especializada sobre o conceito de génio - ela que, por esta altura, valia ao génio um lugar de destaque entre os mais prementes problemas filosóficos da época, suplantando em muito a importância dada às outras recém-promovidas categorias estéticas, como o gosto, ou o engenho.

Um dos autores que se interessaria pelo problema do génio é Kant, que trata o problema nas suas "Lições de Antropologia", entre 1772 e 1796. Kant aborda aí o tema cinco vezes; quatro referindo-o expressamente no título da lição, e uma sob o título "Von den Gemühtsfähigkeiten" (Busolt). ${ }^{14}$ Sem excepção, Kant inscreve o assunto na fase final da parte teorética das Lições, antes dos estudos práticos sobre prazer e desprazer; e não raras vezes, e ainda menos fortuitamente, as lições sobre génio estão directamente rodeadas de lições versando "Witz und Urtheilskraft", as "Gemüths-Fähigkeiten", as "Obern Erkenntnis Vermögen" ou "Vom Talent": no fundo, temas que em geral são já afins ao génio, mas que em Kant estão ainda mais especialmente relacionados, e influíam ainda mais sobre este.

A meu ver, duas formas de ver a questão do génio, por certo diferentes, mas não indissociáveis, são possíveis em Kant. Uma primeira, mais específica, é-nos dada ao nível do texto, e prende-se com a noção de génio em geral (III.); uma segunda parte destes dados e dá-lhes nova expressão, sob a forma da singular visão kantiana de génio (III. 1 e III.2).

Assim, Genie, diz Kant em "Menschenkunde", e não contrariando a história do termo, "provém de genius, que significa um espírito próprio que sempre

14 A saber: "Genie" (Collins, AA, 25.1: 167-170); “Vom Genie" (Pillau, AA, 25.2: 781-784); "Vom Genie" (Menschenkunde, AA, 25.2: 1055-1066); "Vom Genie. 21" (Mrongovius, 1310-1315); "Von den Gemühtsfähigkeiten" (Busolt, AA, 25.2: 1491-1499). 
acompanha o homem, que lhe é associado logo à nascença e o governa" (AA, 25.2: 1056). "Genie", diz aliás Kant, "não vem do francês; mas sim" [originariamente] "da palavra latina Genius", a qual significava "entre os Romanos o espírito propriamente dito do homem, que começa com o nascimento e termina com a morte." (id.: 1493); e por conseguinte, génio, mesmo na sua acepção corrente, nunca ser senão "um espírito próprio": uma origem conceptual que é como "uma espécie de metáfora e alegoria" (id.), própria do espírito generalizante comum a todos os homens.

Só que, aduz Kant, esta origem, embora real, pouco tinha a ver com o sentido que à época era tributado ao termo (ibid.). Pois, aduz Kant, génio provém não só de "Genius[,] espírito próprio" (id.: 1310), mas também "de gignere" (id.: 1056), ingenium, conceito pelo qual os Antigos entendiam "constituição e qualidade naturais de uma coisa" (id.: 1310); e portanto, "por espírito", diz Kant, "não se entende nenhum espectro, mas sim que o espírito tem no homem algo próprio que não tem em comum com outras coisas" (id.: 1056). Isto é, o espírito "não [é] propriamente genie, mas um puro ingenium" (id.: 1493): pura originalidade e inventividade, fruto de uma originária concorrência de talentos; e portanto, as criações do génio "têm de nos ser já inatas e, por assim dizer, próprias da nossa natureza" (id.: 1056).

Ora, para além destes, outros atributos do génio em Kant, todos sedimentando a imagem deste enquanto ingenium, poderiam ser veiculados: o génio é "espírito original" (id.: 167); "arquétipo" (id.: 1492); "inesperada propriedade de um dom natural" (id.); ou "originalidade da imaginação" (id.: 1493).

Mas, segundo creio, se há características globais, e que realçamos aqui como sendo para Kant as principais do ingenium, são a inimitabilidade (Nachahmbarkeit) do génio, fruto da unicidade que é a do acto da sua geração, e porém a sua indole digna de imitação (Nachahmungswürdigkeit), que decorre não só do prazer de embarcar na liberdade do mesmo, como da subsequente elevação desta nova liberdade a modelo.

Assim, diz Kant sem excepção, o génio é uma geração espontânea e singular do indivíduo. O génio é pois original, e é-o tanto nas suas criações, como na sua disposição: pois, aduz sobre isto Kant em Menschenkunde, "original significa 1) negativamente, aquilo que não é imitado, 2) positivamente, quando algo é digno de ser imitado, por não ser uma reprodução, antes pode ser designado um original que merece ser imitado" (id.: 1056).

Assim, por um lado, negativamente visto, o génio é original, e nessa originalidade nem é imitado, nem é imitável; pois, reitera Kant, o puro ingenium é extraído do próprio sujeito, e, porque não há dois sujeitos iguais, então isso significa que tão-pouco há duas genialidades iguais. O ingenium é dom da 
natureza, e único: e portanto "as criações têm de nos ser já inatas e, por assim dizer, próprias da nossa natureza" (id.). O génio, dir-se-ia pois, não pode ser aprendido ("aprendizagem é imitação" (ibid.)); e se assim é, então, "a força inventiva é contrária à imitação" (id.: 1494); pois "no emprego dos talentos", diz o filósofo, "tem de estar algo próprio" (id.: 1056); e se "a natureza tiver sido madrasta no nosso provimento", então, por certo poder-se-á sempre recorrer à "aplicação" (Fleiß), ou ao mecanismo (id.: 1056); mas estes não podem compensar o génio, pois "O génio tem de existir por natureza [...], nenhum professor no-lo pode dar, apenas a natureza, e ele tem de brotar do homem" (id.).

Mas por outro lado, diz Kant, há ainda na originalidade do ingenium uma outra face: pois se, negativamente visto, o génio é por certo inimitável, porém, positivamente visto, e apesar das restrições à sua imitabilidade, ele merece ser imitado!

Pois, por certo, o génio pode ser visto por um prisma exclusivo, segundo o qual o génio é intimamente individual, fruto de um dom superior cuja superioridade não lhe advém da mera contingência, mas sim da prova de ser por outros por ele não agraciados inaprendivel; pois, também para Kant, ele nasce de uma espécie de anomalia, um desproporcionamento, uma aberração que o próprio emissário talvez não saiba explicar, mas que Kant elucida dizendo que "O génio está fundado sobre a desproporção, como um aborto em que alguns membros estão mal estruturados, mas que de resto tem membros saudáveis" (id.: 1058-1059). E o desproporcional, é sabido, não pode nem deve ser imitado. Mas - diz-se - há outro modo de ver o génio, e apesar dessa anomalia, que é pressentível nos poucos membros mal-proporcionados que sempre conferem à genialidade uma marca de estranhamento, outros membros há, diz Kant, que são saudáveis - e a sua percepção, talvez juntamente com a dos membros desproporcionais, pode mostrar-nos o génio sob uma luz deveras singular, segundo a qual, ao surgir, o génio busca uma nova proporção - se não para si, que sempre tem de preservar algo do seu carácter desproporcional, pelo menos para a sua criação. Assim, dir-se-ia, há algo no génio que, tendo nascido do erróneo, talvez nem por isso tenda para o erróneo, antes tende para a sua correcção, e não apenas para uma correcção, mas para uma perfeição inusitada, difícil de pressentir em algo que nascera tão enviesado e torto. Ora, justamente esses membros saudáveis do génio, que são até a maioria, dão lugar a uma outra possível visão do génio: uma visão positiva (enquanto ingenium) segundo a qual, tendo nascido da desproporção, o génio tende pela sua inventividade para a proporção; tendo nascido inimitável, ele merece porém ser imitado! E o que não pode ser imitado, mas justamente nele merece ser imitado, é o que faz dele ingenium: uma transgressão das regras que se afigura ao espectador como algo 
diferente, que justamente é invenção e inovação - e que ao inovar, como que espontaneamente faz esquecer o carácter meramente negativo do génio, segundo o qual ele é inimitável por nascer de uma desproporção, e causa no espectador não o desprazer de saber no génio uma singularidade monstruosa, mas $\operatorname{sim} o$ prazer estético de nele ver a possibilidade de abandonar as regras estipuladas; numa palavra, a certeza de o saber antes um novo modelo [Muster], algo que, embora inimitável, merece porém ser imitado, e causa prazer. E portanto, dirse-ia, se negativamente o ingenium é original e inimitável, positivamente visto, porém, e justamente porque "O génio é uma liberdade sem orientação e coerção de regras", e porque ele é "princípio da novidade das regras, pois, dir-se-ia, ele dá novas regras, e por conseguinte não segue a orientação das antigas regras" (AA 25.2: 784), o génio é modelo.

São estes, pois, reitero, os principais traços do génio em Kant: traços em torno dos quais Kant constrói uma imagem primordial de génio, e que no fundo muito ligam o seu conceito de génio ao que vimos surgir na Europa no século XVII.

Mas porque tais características, embora importantes, parecem não distinguir ainda Kant da massa de teóricos do fenómeno do génio, importa perguntar se, nas suas lições, Kant apenas via o génio como um raro, inaprendível dom, ou se Kant antes discerne no génio outras capacidades, não tão rígidas, mais orgânicas, com respeito ao todo do espírito humano. Numa palavra, queremos ver, por certo baseando-nos nestes traços principais, se Kant não trilha a partir daqui um caminho apenas seu, que o distingue enquanto pensador do génio; e por isso, propomo-nos investigar se Kant não encontra para o conceito de ingenium uma posição privilegiada no próprio sistema do seu pensamento, e se essa posição não se repercute numa acção vantajosa deste sobre as diferentes faculdades do ânimo humano.

III. 1 A origem do problema do génio. O génio como força agregadora do ânimo, e a tarefa de unir imaginação e entendimento

Salientámos já que, ao se apreciar a parte teorética das Lições de Antropologia, as observações sobre $o$ génio surgem num singular enquadramento: entre as superiores e inferiores faculdades do ânimo, ou entre faculdade de imaginação ou prazer e desprazer - temas que, por ora, pouco aparentam ter a ver uns com os outros, e cuja real conexão com o génio é desconhecida.

Pergunta-se, pois, qual é o enquadramento do génio entre tão díspares temas e, se é que nos podemos arrogar a tanto, se o génio pode ser visto como um pólo aglutinador destes. Para tanto, partimos de um ponto anterior nas Lições, na esperança de ver se este desemboca na nossa temática, e que imagem do génio disto pode resultar. 
Na génese da compreensão do génio em Kant, antes mesmo de se poder falar no problema do génio enquanto tal, está a questão da difícil compatibilização das diferentes faculdades do ânimo. Assim, diz Kant em "Die Sinnlichkeit" (Collins, AA 25.1: 31-35), como em outras lições de tema afim, existem no ânimo faculdades opostas; e estas não só se opõem no seu procedimento, como, de acordo com o mais ou menos relevante papel que assumem no ânimo, são por Kant designadas ou inferiores, ou superiores. A saber, as faculdades inferiores são a sensibilidade, ou a imaginação, que tornam a representação do conhecimento intuitiva, e a apresentam ao escrutínio do entendimento, e as superiores são justamente o entendimento, que ajuíza essa mesma representação, e a razão, que ulteriormente a deduz (cf. AA, 25.2: 782). Uma, reitera Kant, é a faculdade do ânimo cujas representações "sensíveis" (AA, 25.1: 31) são facultadas à outra, o entendimento; outra, este mesmo, que ou as julga conformes ao modelo da verdade, ou as julga erróneas, e rejeita-as. A sensibilidade, a imaginação, dir-se-ia pois, são a "passibilidade [...] do ânimo" (AA, 25.2: 738); a faculdade de julgar, o entendimento, a "espontaneidade" auto-activa "do ânimo" (id.). Uma, diz Kant, é sensibilidade: ela é "potestas executoria" (id.: 486), opera com intuições e sensações, e, enquanto tal, é "instrumento passivo do entendimento" (id.: 487), daí se supondo a sua inferioridade; o outro, ao invés, é intelectualidade: ele é "potestas rectoria do ânimo" (id.: 486), trabalha apenas com "conceitos" (id.: 1228) e dirige-se já não para o possível, mas para o real conhecimento do objecto, daí advindo a sua superioridade.

Assim, dir-se-ia, na génese do problema do génio está uma divisão entre sensível e intelectual, e parece ser para Kant importante que sempre se faça notar que imaginação e entendimento têm diferentes propriedades e funções na actividade cognoscente do espírito. Mas, ao mesmo tempo, aduz Kant, tem de haver entre sensibilidade e entendimento uma ligação - de outro modo, não haveria conhecimento; e portanto, do facto de que estas faculdades sejam opostas, de que elas tenham mais ou menos nobres ofícios, e que elas criem representações de diferente índole, não se conclui porém nem que elas devam permanecer separadas, nem que não possa haver um qualquer elo entre as suas imagens. Pois, diz Kant, o entendimento julga, e é por certo "sublime" (AA, 25.2: 738) na sua função censora; ao passo que a sensibilidade, muito por culpa da sua heteronomia, é senão mais rude, pelo menos menos selecta - ela dá ao entendimento uma torrente de impressões, e daí lhe são imputados vários perigos, alguns deles injustos. ${ }^{15}$ Mas, ao mesmo tempo, se o entendimento rebate estes argumentos nas várias versões da sua apologia da sensibilidade, AA 25.2: 887, 1230). 
é indispensável para o pensar humano, porém ele não o é tanto quanto a sensibilidade, a qual é "ainda mais indispensável do que o entendimento" (id.); pois é ela que lhe dá "matéria para todas as coisas" (id.), sem o que ele seria "sem sentido" (ibid.). ${ }^{16}$

Assim, dir-se-ia, a sensibilidade tem de ter uma ligação com o entendimento; e se por certo não a tem quando assoberba o entendimento, e o obriga a rejeitar as suas impressões, porém, diz Kant, ela poderá tê-la sob dois pressupostos: por um lado, se a sensibilidade for vista não apenas na sua faceta inferior, menos refinada, e puder ser vista como um instrumento útil ao entendimento, cujas produções este venha a aceitar e a incorporar no seu corpus de verdade; e, por outro, se também o entendimento puder ser disposto para aprender o seu benefício nesta diferente relação com a imaginação. Isto é, imaginação e entendimento terão uma salutar ligação se os perigos da sensibilidade puderem ser de alguma maneira "disciplinados" (AA, 25.1: 486), de tal modo que a sensibilidade possa ser tida como uma "ferramenta do entendimento, que ele emprega para tornar as suas ideias intuitivas" (id.). Pois este é, no fundo, o intento de Kant: a saber, que sensibilidade e entendimento possam ser trazidos a uma disposição única, um ponto de equivalência vantajoso para ambos, o único em vista do qual se pode afirmar a perfeição do ânimo humano.

Este problema, creio, é aprofundado em outras lições. Duas delas, porém, são manifestas neste propósito: "Von den Obern Erkentniss-Kräfften der menschlichen Seele" (AA 25.1: 147-158) e "Von dem Unterschied der Sinnlichkeit und Verhältnis gegen den Verstand" (id.: 485-487).

Aí, sem surpresa, vinca Kant a referida cisão entre entendimento e sensibilidade, baseando-a sobretudo nos perigos da sensibilidade (cf. AA, 25.1: 486). Mas procede não alimentando esta cisão, antes salientando que a potestas "rectoria é sem a executoria cega" (id.: 486), e que portanto rectoria e executoria, ambas são "necessárias para a perfeição" (id.); pois a perfeição não consiste em que subjuguemos as nossas faculdades, antes "em que possamos submeter as nossas faculdades e capacidades ao livre arbítrio" (id.: 485, 1231). O problema, diz porém Kant, é que se havemos de o poder fazer, então não pode haver apenas cisão, ou apenas aspiração à união; tem de haver, sobretudo, "ainda um poder e uma força que traga ao exercício um tal arbítrio, de onde proceda o livre arbítrio." (id.: 485-486) Isto é, há uma "subtil, pequena fronteira" (id.: 1313) entre o excesso e o apagamento da imaginação perante o entendimento; e

16 "O entendimento não pode executar nada, antes é a sensibilidade que tem de the dar matéria" (AA, 25.1: 486); "[...] a sensibilidade [...] é ainda mais indispensável do que o entendimento" (AA, 25.2: 738); "Sim, quase poderíamos prescindir antes do entendimento do que da sensibilidade." (id.: 1230). 
por conseguinte, tem de haver uma força suplementar que regule esta possível união entre duas tão contrárias entidades; a saber, que por certo disponha correctamente o entendimento, e que também discipline a imaginação, e isso em dois sentidos: por um lado, porque a imaginação não é coisa de todos, para que ela, "que tão mal se submete ao livre arbítrio" (id.: 486), seja trabalhada (excoliert) e tenha empregabilidade; mas por outro, porque ela pode levar ao erro, para que esse estímulo não degenere no excesso (exaggeratio (AA, 25.2: 1491)), e para que, diz Kant, "as suas forças não sejam demasiado grandes em proporção para as forças do entendimento" (id.: 486). Pois aquela é a palavrachave, e este é o momento-chave do problema: a saber, Kant visa aqui algo que una as diferentes faculdades, mas sobretudo que possa criar entre elas harmonia e proporção. Pois ao se visar a perfeição das coisas, não importa o grau ou a intensidade da faculdade, "mas sim a proporção das capacidades do ânimo" (id.: 1491): pois é ela que dá beleza ao todo: "A mal disposta proporção das forças do conhecimento torna tudo mau" (id.: 147); "A desarmonia e desproporção constitui a fealdade" (id.). E portanto, não importa para a questão se o entendimento é fraco, ou a imaginação forte; importa, isso sim, se pode haver entre estes uma bela proporção: a saber, um conflito de forças contrárias, mas não cada qual pugnando pelo seu grau, antes cada qual adaptando-se dinamicamente ao avanço da outra, de tal modo que se crie entre estas uma oscilação viva e bela: uma união, malgrado sob esta ter de subsistir o conflito. E até que esta força suplementar possa ser nomeada, e tal proporção criada, não há esperança de que as faculdades do ânimo venham a unir-se: nem que a sensibilidade venha a ser algo que não uma ameaça para o entendimento; nem que o entendimento possa ser um "são entendimento", ao qual se deve "ter tanta pretensão como à própria humanidade" (id.).

Numa palavra, conclui Kant agora em "Von den Gemühtsfähigkeiten" (AA, 25.2: 1491-1499), "Tem de ocorrer entre as forças do ânimo uma proporção" (ibid.): a saber, uma inimitável, mas digna de imitação proporção dos talentos; e portanto, o que se visa é aquilo que tem de estar na base de todas a actividade humana, ou então para além desta, como seu modelo: a bela re-disposição das faculdades do ânimo, suscitando prazer, agrado, e ocultando a desproporção que existe entre estas, da qual resulta desagrado (cf. $i d .:$ 1491). Ora - e aqui está o cerne da questão -, se a proporção não está ao alcance de variações dos talentos, então, para Kant, também só a poderá obter quem não se deixar incorrer na rotina, no hábito de tais variações: quem souber, justamente, reproporcionar as quotidianas posições das faculdades do ânimo. E portanto, uma tão difícil e original disposição do espírito humano, a criação de um modelo original para as diferentes faculdades do espírito, não está ao alcance de todos; a elas, apenas 
aspira um só: o espírito "inventor" (ibid.), e só é inventor quem tem por certo o talento, mas também o natural em conjunto (ibid.): quem cria "o modelo para outros", quem é "arquétipo, e não imita" (ibid.) - quem "faz de um objecto uma regra" (ibid.) inimitável - a qual, porém, pode e deve ser para outros digna de imitação. Numa palavra, pode aspirar à proporção entre faculdades do ânimo, e à bela união entre estes, justamente o génio, enquanto ingenium: o que tem espírito original, que sempre faz "um original para imitação" (ibid.), e que para isto usa "originalidade da imaginação" (id.: 1493), tentando com esta alcançar harmonia entre as forças do ânimo. Pois, di-lo-ia Kant, o ingenium não é nem um mero talento, nem uma faculdade do ânimo, antes uma força ou capacidade intermédia do ânimo, a qual, situada entre entendimento e imaginação, cria entre estas uma original disposição, uma proporção de índole estética que conduz à boa união e favorecimento das mesmas - é aliás essa a visão que distingue Kant dos seus contemporâneos, e singulariza a sua visão sobre o tema.

III. 2 A proporção entre faculdades do ânimo, ou a árvore do génio

Posto isto, pergunta-se: como divisa Kant uma tão singular, tão inimitável, quanto digna de imitação, proporção entre faculdades do ânimo, como é a do ingenium?

O problema da proporção do génio, decisor de toda a questão, é tratado por Kant em "Vom Genie" (AA, 25.2: 1055-1066), e na referida lição de Busolt (AA, 25.2: 1491-1499), as duas mais detalhadas lições sobre génio. Aí justapõe Kant não só imaginação e entendimento, como também os rebentos destes. Assim, diz Kant, "Podemos comparar o génio com uma árvore" (AA, 25.2: 1062), na medida em que, rebentando o génio nas raízes, ele manifesta-se na faculdade de julgar; na coroa, o génio surge no "proeminente talento" (id.) da imaginação; rebentando este na flor, ele manifesta-se no gosto, e rebentando ele no fruto, surge no espírito. A imagem do génio é, pois, quadripartida; e todos os talentos têm aí o seu legítimo lugar. Mas, não obstante, há nesta quadripartição diferentes dinâmicas, e também diferentes valências: pois faculdade de julgar e imaginação são, dir-se-ia, basilares, tal como o são as raízes e a copa de uma árvore; eles são, pois, os elementos principais na proporção visada pelo génio; e eles têm relação directa com cada um dos "produtos do génio [...], espírito e gosto" (AA, 25.2: 1495), a saber, o gosto depende da faculdade de julgar, e o espírito da imaginação; o que, por fim, forja como que uma organicidade implícita entre elementos.

Não perdendo tempo, Kant passa a reformular o problema.

A questão está em que, sendo imaginação e faculdade de julgar naturalmente opostos, isso faz com que os 4 elementos divirjam entre si; o que é visível, na 
medida em que o génio não só pode rebentar em qualquer um deles, como, ao fazê-lo, parece dar a cada um destes preponderância, o que se repercute em diferentes espécies e criações do génio; e isto, a ponto de até povos serem com esta desproporção conotados. Ora, embora isto se reporte a meras manifestações do génio, aqui se revela porém uma real desproporção dos talentos; e, aduz Kant, ela existe independentemente do ponto para que penda. Assim, a criação do génio é necessariamente uma imagem; e mesmo que a vejamos à luz desta árvore, e a distribuamos pelos seus quatro pontos cardeais, ela é sempre um produto da imaginação que é trazido à faculdade de julgar, que a julgará boa, e portanto consentânea com a verdade, ou má, e portanto falsa. Entre as representações boas, porém, ela pode ainda denotar gosto - se afim ao entendimento -, e espírito - se também afim à imaginação. Mas se o génio nesta pender para 0 entendimento, então, diz Kant, o entendimento mostrará uma notória aridez e inflexibilidade, e por fim insipidez; se pender para a imaginação, o génio sempre corre o risco de extravasar, e a imaginação dar lugar ao ludíbrio da faculdade de julgar; e, como já se depreende, ou o gosto é afectado, ou até anulado, ou então ele torna-se opressivo. E portanto, tal como uma árvore não pode ter uma copa viçosa sem raízes fortes, ou dar fruto sem flor, também o ingenium tem de alcançar proporção entre elementos, fruto de uma disposição original entre faculdades; de outro modo, não dará flor ou fruto: "Pois onde uma força faltar não há nenhum génio" (id.: 1495).

Assim, pensemos o binómio principal da árvore do génio, a saber, faculdade de julgar e imaginação, à luz da sua normal disposição no processo cognitivo. A faculdade de julgar é neste a raíz: e isso não porque o processo representativo nela se baseie, mas porque ela é ofirme tronco da árvore do génio. Pois, do alto da sua primazia como faculdade do conhecimento, é dela que procede a exigência de proporção (no fundo, de gosto), e é a ela que também o génio, enquanto capacidade ou força do ânimo, tem de reportar ulteriormente. Na sua normal disposição, dir-se-ia pois, a faculdade de julgar ajuíza sobre a conformidade à verdade, isto é, o gosto das representações; e isto, fá-lo ela em relação à imaginação, a qual, vista por este prisma, é copa por ser a multiplicidade de impressões e representações vindas dos sentidos, as quais, tornadas imagem, são então submetidas a escrutínio. A imaginação, dir-se-ia pois, é livre, oscilando a seu contento, como uma copa - e nisso, sempre vive na possibilidade de suscitar espírito - mas não inteiramente livre, pois sob si tem um sólido sustentáculo, a faculdade de julgar, que exige gosto e a impede de, no turbilhão do espírito, vergastar a árvore, ou até arrancá-la de uma vez pela raíz!

A normal disposição do espírito, vê-se pois, implica já de si uma necessária desproporção, uma forçosa desarmonia, segundo a qual a faculdade de julgar, 
enquanto raíz da árvore, é superior em força à copa da imaginação; aliás, ela é assim apenas para evitar uma ainda mais perigosa desproporção, que ocorre sempre que a imaginação assoberba o entendimento. Ora, pensa Kant, o entendimento é naturalmente superior, e tem de censurar, e a imaginação naturalmente inferior, e tem de representar - e estas são regras imutáveis, quer numa normal, quer numa singular disposição do ânimo; mas se ambas resultam em desproporções, então a proporção tem de estar numa intermédia disposição de forças-por muito que por intermédia se tenha de entender aqui uma original disposição do espírito. Assim, a imaginação não pode ser submissa, como na normal disposição do espírito, nem totalitária, como numa insensata disposição do mesmo; pois isso traz desproporção dos talentos. Ela tem de, dir-se-ia, pelo menos equivaler-se às forças da faculdade de julgar, e o que isso implica é que ela estenda os seus ramos, abra para o campo do seu jogo e cresça viçosamente, por certo não ultrapassando a faculdade de julgar, mas logrando que algumas das suas representações ( $o$ seu fruto) o façam; ou, se o quisermos, fazendo com que, da sua torrente de impressões, apenas quebrem a barreira do entendimento não aquelas que o entendimento é impotente para travar, mas aquelas que o entendimento não pode senão anuir - como o são as representações geniais que trazem consigo gosto e espírito. Pois, reitera Kant, é certo que "A imaginação e a disposição para a mesma têm de ser no génio extraordinariamente grandes e ao mesmo tempo controladoras" (AA, 25.2: 1493). Mas porque, neste ponto intermédio, "sob as regras do entendimento ela é sempre interrompida, o que, por assim dizer, lhe corta" [à copa] "as asas" (id.), e "A imaginação [...] tem de estar também sob regras", então, tem de ser possível uma disposição única em que a imaginação alcance os dois pressupostos, e ao mesmo tempo "não se detenha em limites, e porém não contradiga o entendimento" (id.: 1494). E isto é possível, diz Kant, porque ela é "originalmente própria e não imitada" (id.), porque da sua flor emerge "liberdade e originalidade da imaginação" (ibid.), e portanto o seu fruto dá "azo a novas regras" (ibid.) - isto é, tal é possível se a imaginação denotar génio, ou se, na criação do génio, a imaginação for disposta de tal modo que seja livre, e porém proporcional às outras faculdades, e portanto criativa sem ferir o entendimento: "Se ela se submeter apenas a leis onde a sua maior liberdade ocorra, em que se dê a mais feliz consonância com a maior determinidade possível do entendimento e da razão, então ela tem a disposição que é exigida para um génio" (id.).

Assim, dir-se-ia, o génio é uma possibilidade de libertar e ampliar a imaginação, sem que com isso a ela se feche o entendimento. Ele pressupõe um reproporcionamento das faculdades do ânimo, não só com respeito à sua disposição, mas também à sua possível concórdia mútua. Mas a alavanca que 
engendra a tão desejada proporção entre raízes e copa da árvore do génio, é na verdade não a imaginação, ou o entendimento, mas a flor e fruto destes, os quais, mediante a criação de novas e inimitáveis imagens e regras, no caso do espírito, e na assumpção destas como um modelo digno de ser imitado, no caso do gosto, criam organicidade entre as partes, e elevam o génio como dom criativo do espírito humano. Resta-nos ver como isto é proposto.

O tema é abordado nas lições sobre génio.

Flor e fruto do génio, gosto e espírito, diz Kant, são produtos do génio. Mas, diz também o filósofo, "o essencial do génio não é a flor" (id.: 1062), a qual depende do entendimento, e só pode surgir enquanto tal após a acção da imaginação. O essencial do génio é o espírito - a ponto, aliás, de não raras vezes Kant achar a expressão mais apropriada para designar génio (cf. id.: 782,1494). "Espírito", diz-se, "é aquilo que vivifica, quanto mais espírito existir, tanto mais vivificação se dá através de ideias puras, mediante o que a actividade da faculdade de conhecer é toda ela movida harmoniosamente." (id.) Numa palavra, pois, o espírito vivifica; e dessa vivificação resulta génio, e também a desejada harmonização das faculdades na árvore do génio, e a ulteriormente visada "actividade da faculdade de conhecimento" (id.). Ora, isto é evidente. Mas, diz Kant, a questão põe-se porque, sendo o espírito evidente, ele é ao mesmo tempo "a parte mais insondável [do génio]" (id.: 1063), e aquilo que nas criações da imaginação vivifica ( $i d$.), é de difícil percepção, a ponto de esta "ser tão impossível, quanto o é agarrar um espírito na sua aparição" (id.). E portanto, o espírito poderá até ser inimitável e digno de imitação; mas o que faz deste o que ele é; o momento vivo que o define, em vista daquilo que sempre tem de se lhe opor - a faculdade de julgar -, afigura-se algo quase inapreensível, e difícil de descrever; e porém, sugere Kant, é essa aproximação possível ao cerne que é necessária para se compreender não apenas o espírito, mas aquilo que é o principal no processo de proporcionamento das faculdades mediante o génio.

Kant procede nesse ensaio de elucidação do espírito; não apenas em uma, mas em várias lições sobre o tema, que tentaremos aqui reconstituir numa só visão.

Assim, vista apenas por si só, a imaginação seria fantasia: e a fantasia, enquanto capacidade de reprodução de imagens, cifra-se numa produção incontida de imagens, tantas quantas dos objectos vierem aos sentidos. Talvez por isso, Kant dela diga que "A fantasia é igual a uma actividade infatigável, ela é, por assim dizer, uma torrente de imagens que para aí flui incessantemente." (AA, 25.1:314), e que, à falta de um freio, "Temos tão pouco poder sobre a nossa imaginação, como sobre a corrente do nosso sangue" (id.: 312). Ora, esse freio existe; ele é a faculdade de julgar, a qual, perante este cenário, se oferece como 
barragem, e rejeita este excesso. Mas, para Kant, a imaginação não é apenas fantasia, tal como a faculdade de julgar não é apenas entendimento; e muito menos é a imaginação do génio fantasia, e muito menos o entendimento pode rejeitar esta sem mais. Bem pelo contrário, diz Kant, "no génio, a imaginação tem de ser de tal modo, que [respire] espírito" (AA, 25.2: 1494). Isto é, no génio, a imaginação não pode ser aleatória, irrefreada como o é na mera fantasia. Ela pode e certamente tem de partir da fantasia; mas, ao invés de se deixar ir na torrente desta, ela, num forçoso acto de auto-disciplina, faz emergir dessa torrente não as imagens que são meras imagens de objectos, mas (por certo com o concurso do engenho) aquelas imagens que são dos objectos ideias, isto é, que são dos objectos as mais originais e inimitáveis, mas também plausíveis e dignas de imitação percepções, e que por isso "são vistas como os originais das coisas". (id.) E isto, fá-lo ela discernindo não apenas conexões originais entre as coisas, mas antes constructos de conexões originais, os quais, devido à sua nova índole, a faculdade de julgar se mostrará renitente em rejeitar, e o entendimento inclinado para associar ao tesouro de verdades humanas.

Assim, diz Kant, o espírito é a mais insondável parte do génio; e é por certo difícil descobrir o que é vivificante nas criações da imaginação (cf. $i d$.: 1063). Mas, diz Kant, pelo menos uma coisa é certa: no génio, a imaginação procede estabelecendo conexões originais entre os objectos, e dessas conexões sai não apenas uma nova imagem (o que seria o engenho), mas antes uma nova disposição, uma nova ideia, todo um novo modelo dos mesmos (cf. id.: 1064). Pois o que a imaginação faz no génio é extrair o "original das coisas" (id.: 1494) - como se delas extraísse não só algo novo, mas justamente o espírito destas, o qual ela faz aparecer sob uma roupagem nunca antes vista, cuja impressão por certo choca no início, mas depois gera prazer, e torna-se delas modelo (criando para estas novas regras, gosto). O espirito das coisas, dir-se-ia pois, é no génio transposto para a ideia, e por fim para a palavra, como é o caso na poesia - e nessa transposição consiste o espírito, ou génio. Talvez por isso, quando perante um destes constructos da imaginação, como o é a poesia, "Notamos que uma expressão de um poeta pode fazer uma impressão tal, que todas as forças do nosso ânimo são movidas, o nosso engenho começa a entrar num jogo, e o nosso entendimento recebe matéria para pensar" (id.: 1063). Sim, pois a poesia é por certo o elemento natural do génio; pois também ela não pode ser feita com aplicação, mas apenas por talento, ou artes geniais; e por conseguinte, aquando do acto de poetar, da torrente de sensações e imagens que é recebida dos sentidos, e com que a fantasia trata, a imaginação recolhe o essencial, o original - o espírito das coisas - e, animando-o, fá-lo viver para além do objecto, no ânimo do espectador. Por isso é que, no momento de inspiração 
poética que é o do génio, dá-se espírito - dá-se algo como entusiasmo poético (Begeisterung), - para o que é exigido algo "que se chama ideia especial, que consiste em extrair das coisas o essencial que nelas reside, onde o restante é meramente um suplemento em relação àquilo que constitui o verdadeiro fruto de certos conhecimentos" (id.: 1064); e embora, quando este surge na palavra poética, "não se possa dizer onde ele reside" (id.), e ele seja irreconstituível, a ponto de tal não mais vir ao sentido ainda que tentemos (cf. id.: 1310), contudo, no referido momento, "parece que ingerimos uma certa semente para conhecimentos, e somos impregnados com novos pensamentos; enriqueceuse os seus talentos com novas ideias" (id.: 1064). E aí, e só aí, no derradeiro esforço dos talentos, no ulterior passo da sua originalidade-, se dá no génio o "genuíno espírito" (id.).

Ora, posto isto, pergunta-se por fim: no momento de enlevo poético, no espírito, no génio, como procedem a imaginação e o entendimento, especialmente com respeito à tão desejada proporção entre si, e entre os seus rebentos?

A resposta, creio, é óbvia: pois o entusiasmo poético, o espírito, não é de todo um fulgor insensato do sentimento, uma brecha através da qual a torrente de impressões possa furar a oposição do entendimento; nem é ele total subserviência em relação a este. Não; bem pelo contrário, o assoberbamento, a suplantação do entendimento, ao ocorrer, é apenas a necessária para que, no recuperar do sentido pelo entendimento, este seja ainda supremo na sua função censora, e a imaginação porém livre na sua acção criadora - nem mais, nem menos do que isto. A imaginação, dir-se-ia pois, é aqui não rude, mas plena de sentido, não absurda, mas circunspecta no seu trabalho com o entendimento. Por conseguinte, na visão de Kant dá-se aqui um importante fenómeno, a saber, que no fazer poético (poiein), e no génio para isto requerido, a imaginação perde o seu irrefreamento, mas ao mesmo tempo não abdica da sua licença. Isto é, ao mesmo tempo que se despoja de adornos, e de entre a torrente de representações escolhe aquelas que são originais das coisas, assim atendendo à exigência de verdade do entendimento, no génio, a imaginação não leva o seu disciplinamento tão longe que não possa também ser criativa no seu jogo - ou seja, de tal modo que estes originais, estas ideias especiais não possam criar prazer, e tornar-se modelo; e neste precário, mas infinitamente produtivo equilíbrio, a imaginação, o espirito, copa e flor da árvore do génio, apresentam à faculdade de julgar imagens não só válidas, mas inauditas das coisas, dir-se-ia, "semente para conhecimentos" e "novos pensamentos" (id.: 1064) - no fundo, assim preenchendo um dos requisitos de proporção entre diferentes faculdades do ânimo. 
Mas, ao mesmo tempo, um segundo fenómeno é posto em marcha. Pois, por seu lado, a faculdade de julgar acompanha todo este processo; pois, enquanto raíz da árvore do génio, ela é também origem, e não apenas sustentáculo do mesmo. Mas se a faculdade de julgar assim se apresenta, então, que significa para si esta contida incontenção da imaginação, como ela ocorre no génio? A isto, responde Kant: não, por certo, um mero apaziguamento da imaginação; nem o sobrepujamento do próprio entendimento. Ao invés, o que é visado no refrear das forças da imaginação é antes a equalização, ou subsequente sintonização (Glückliche Zusammenstimmung, id.: 1494) da imaginação com $o$ entendimento, até um ponto em que as suas forças coincidam com as daquele, e em que, mesmo que as ultrapassem, como é o caso no espírito poético, não o façam senão para apresentar ao entendimento benéfica inovação, e por conseguinte progresso que ele não teria alcançado por si só. Por outras palavras, o refreamento da imaginação a que Kant se refere é decerto um refreamento, mas também e sobretudo um singular e cumulativo processo de homogeneização e aperfeiçoamento - e isso, tanto da imaginação pelo entendimento, como também do entendimento pela imaginação (cf. id.: 1313). Pois, ao se deparar com tão disciplinadas, tão harmoniosas criações da imaginação, como são aquelas do génio, o entendimento nada pode ter a opor; e mesmo quando confrontado com aquela "ideia especial" (id.: 1064) que tudo anima, que é por certo violenta na sua aparição, de seu nome entusiasmo (Geist), o entendimento, embora momentaneamente assoberbado, nada lhe opõe, e ao invés de a negar, reconhece-lhe gosto, ${ }^{17}$ e concede-lhe entrada no tesouro de verdades do ânimo humano. A razão de ser desta concessão, aliás, é evidente. Pois aquilo que no génio é apresentado à faculdade de julgar não mais são imagens desconexas, e portanto falsas aparências das coisas, mas sim veras ficções, ilusões dos originais das mesmas - a essência, perante o que tudo o resto é superficial -, e portanto, dir-se-ia, a verdade das coisas, uma gadanha que o entendimento bem conhece, e no fundo a única que aceita; e perante isto, o entendimento baixa o seu bastão censor, e une-se à imaginação no processo formativo, "mediante o que a actividade da faculdade de conhecer é toda ela movida harmoniosamente" (id.: 1494, 1495)). Pois, na poesia - e para recuperar um dos temas centrais no "Opponenten-Rede" (AA XV.2: 903-935) -, o entendimento é por certo iludido; mas, sabendo-se porém em controlo de si próprio, e vendo-se para mais presenteado com verdades sob novas cores, mais sensíveis e para si desconhecidas, o entendimento vem a reconhecer nela não uma opositora, 
mas uma necessária concorrente, e nesta nova matéria que lhe é dada não um embuste, mas um novo, mais rico caminho para a verdade das coisas - assim se cumprindo o segundo requisito de proporção entre as faculdades, e assim logrando união entre os 4 pontos da árvore do génio: “Assim, o génio tem de vivificar a faculdade da imaginação, as ideias, e pô-las num movimento harmonioso e proporcional. Aqui a imaginação é posta em jogo, o entendimento encontra matéria, o engenho diversão, e a faculdade de julgar ocupação" (AA 25.2:1494).

\section{Referências}

"Encyclopaedia Britannica". 18 Vols. Ed. by Thomas Dobson. Philadelphia, 1788-1798. ADELUNG, J. C. "Versuch eines vollständigen grammatisch-kritischen Wörterbuches der Hochdeutschen Mundart". 5. Th. Leipzig: Bernhard Christoph Breitkopf und Sohn, 1774-1786. (GKW).

BAILEY, N. "Dictionarium Britannicum, or a more compleat Universal Etymological English Dictionary". London: T. Cox, 1730. (DB).

BULLOKAR, J. “An English Expositour, or Compleat Dictionary”. Cambridge, 1616 (5 $5^{\text {th }}$ ed. John Hayes, 1676). (EEx).

CAWDREY, R. "A Table Alphabeticall, or the English Expositor". London: Edmund Weaver, 1604 (Uso 4a ed. London: Edmund Weaver, 1617). (TA).

COLES, E. “An English Dictionary”. London: Samuel Crouch, 1676 (Uso edição posterior, London: S. Collins, 1717). (ED).

DIDEROT, D., D'ALEMBERT, J. le R. "Encyclopédie, ou Dictionnaire raisonné des

Sciences, des Arts et des Métiers". 35 Vols. Paris (1751-1772), (Encyclopédie).

DIEZ, F. C. "Etymologisches Wörterbuch der romanischen Sprachen". 2 Bde. Bonn: Adolph Marcus, 1853 (EwrS).

GLADOV, F. [i.e. Sperander]. "A la Mode-Sprach der Teutschen, oder Compendieuses Hand-Lexicon”. Nürnberg: Buggel und Seitz,1728. (SdT).

GRIMM, J., GRIMM, W. "Deutsches Wörterbuch”. 32 Bde. Leipzig: S. Hirzel, 18381961.

JOHNSON, S., WALKER, J. "Dictionary of the English Language”. London: P. Knapton et al., 1755. (DEL).

KANT, I. "Gesammelte Schriften". Hrsg.: Bd. 1-22 Preussische Akademie der Wissenschaften, Bd. 23 Deutsche Akademie der Wissenschaften zu Berlin, ab Bd. 24 Akademie der Wissenschaften zu Göttingen. Berlin 1900ff. (AA).

KERSEY, J. "Dictionarium Anglo-Britannicum: or, a general English Dictionary". London: J. Wilde, 1708. (DAB).

KING, R. F. B. "An Analytical History of the Conception of Genius in English Literature and Thought from 1700 to 1775". Michigan: Palala Press, 1960. (AHCG).

LUDWIG, C. “A dictionary English, German and French". Leipzig: Thomas Fritschen, 1706. (DEGF). 
OUDIN, C., OUDIN, A. "Thresor des Deux Langues Espagnolle et Françoise”. Paris: Antoine de Sommaville, 1645 (TTL).

PERRAS, J.-A. "L'exception exemplaire : Une histoire de la notion de génie du XVIe au XVIIIe siècle". Tese, 2012 (EE).

RICHELET, C.-P. “Dictionnaire François". Geneve: Jean Herman Widerhold, 1680 (DF). SIR THOMAS ELYOT. Disponível em: http:/quod.lib.umich.edu/e/eebo/A21313.00 01.001/1:7?rgn=div1; view =fulltext.

SOMMER, H. "Genie. Zur Bedeutungsgeschichte des Wortes von der Renaissance zur Aufklärung”. Frankfurt: Peter Lang, 1998 (GZBW).

STEPHANUS, R. "Dictionarium, seu latinae lingae thesaurus". Paris: Robertus Stephanus, 1531. (DLLT).

STIELER, K. von. "Der deutschen Sprache Stammbaum und Fortwachs, oder Teutscher Sprachschatz". Nürnberg: in Verlegung Johann Hoffmanns, 1691. (DSS).

VOLCKMAR, N. "Dvictionarium Trium Linguarum, Latine, Germanice et Polonice". Dantisci Impressum, 1605 (DTLL). 